\title{
Research on the Theory of Action Learning Huang Haochen
}

\author{
Wuhan University Of Technology, 122 Luoshi Road, Wuhan, Hubei, P. R. China 430070 \\ 1020700752@qq.com
}

\section{Key words: Plan; Action; Question; Reflection; Learning}

\begin{abstract}
This document attempts to research the action learning theory from five aspects which are emergence characteristics dynamic process key element and result. The action learning process is generally a form of group. The team member get together to help the learner find a solution to the problem. It creates an ideal environment. There are four key elements in the dynamic process of action learning. they are questioning plan actions and reflect. And the learning activity format a cycle. First thing is finding the problem. The learner can reflect the problem from the action learning group. Then learner improve the plan at the group meeting. Finally, learner can execute the plan. The new problem will happen again trough the execution. People are encouraged to express their opinions. They can receive feedback from other members. Learner play a leading role in the mode of action learning. The teacher who plays a guiding role only help students to think in the team. The process of learning is more effective than traditional learning method. The learner should communicate with the team members. These also promote the development of the organization.
\end{abstract}

\section{Introduction}

Action learning method is a procedural concept. It has a rich connotation and meaning. There is no uniform definition in the academic circles. This paper, through the five aspects to research the action learning theory in order to have a more systematic understanding of the theory.

\section{Emergence and development}

The theory of Action learning was first put forward by professor Weinstein. K from UK. He believes learning brings to people the ability to deal with the problem under flexible situation. His idea of Learning can be summarized as a formula: $\mathrm{L}=\mathrm{P}+\mathrm{Q}$, L means Learning.P means a structured knowledge (programmed knowledge). Q means Insightful questions. Structured knowledge generally refers to the ideas which can be learned from traditional forms such as training. But this knowledge unable to cope with complex actual situation. The real learning is creating situations. If the $\mathrm{P}$ means the teacher to the learner's guidance. $\mathrm{Q}$ is the learners own exploring. The professor's guidance must combine with the learner's independent exploration. The learning will be more effective.

Actually, Weinstein. K doesn't give a clear definition of active learning. Formula "L = P + Q" suggests learning must based on the learner's practical exploration. Later, many scholars make further study of action learning. Mike Pedler thinks the main factors are participants, questions, and sharing of the group in practice. It means the win-win result of self development and organizational development in action learning. It depends on questions to solve the problem. There are three aspects of action learning. First, it is a method which needs the help of the group. Second, action learning is based on the practical action to solve the real problem. Third, the action learning can promote the 
development of learners and the development of the organization. Ellen change the formula " $\mathrm{L}=\mathrm{P}$ $+\mathrm{Q}$ " to "L + $\mathrm{P}=\mathrm{Q} 1+\mathrm{Q} 2$ ". He thinks action learning is started in the practical problems or confusion (Q1).Learner have to get some structured knowledge related to problems (P).Finally, he can make a new explanation with the help of the team (Q2). Action learning became a cycle of $\mathrm{P}$ and $\mathrm{Q}$. The process isn't a one-way circulation process from $\mathrm{P}$ to $\mathrm{Q}$. Because the action learning is based on personal reflection. The action is based on the experience. The action learning process is generally a form of group together to find a solution to the problem. Individuals and organizations can both be developed in the process of problem solving.

\section{The nature and characteristics}

Weinstein. K interprets the essence of action learning. He thinks there is no learning without action. Also, there is no action without learning. These two things are closely connected. We can put forward new practical problems with reflection on experience. Action learning must have a collaborative group which members want to share their working conditions or difficulties. Other team members can easily understand the problem of the learner. Individuals in the process may get a new work plan. He can focus on the new plan. The process of the action learning has its unique rules such as secrecy rules. Each participant should comply with the rules. All members are equal in the action learning groups.

Action learning creates an ideal environment. People are encouraged to express their opinions. And they can receive feedback from other members. The characteristics of the action learning are different from other learning methods from several aspects:1 Action learning should accompany by solving practical problems. 2 The learning process is driven by the learners. 3 Personal development is equally important to solving practical problems. 4 Action learning may cause changes in the organization. 5 Action learning is not a short term training, it needs time to accumulate.

This document is believed the characteristics of action learning are mainly reflected in three aspects: Firstly, it's based on the solution of the practical problems in reality. Secondly, it depends on the supporting of the group. Thirdly, action learning is a continuous cycle.

\section{Dynamic processes}

Action learning is a circulation of the "practice - reflection - practice" process as shown in figure 1. Learner should describe problem in advance. The team members help to format a new understanding of the question. Then learner in the learning group establishes a new plan. Finally, learner carries out practice tasks according with the plan. We can test it in practice. It is a constant process of circulation.

Rethink the problem is an important part in the action learning process. It achieves a process of cooperation and reflection in the structured organization. The learner can clearly understand his current situation. Lerner first shows his confusion to everyone on the group meeting. Team participants assist the learner to solve problems. These help just limited to listen and judgment. Team members will not give a complete answer to the learner. The process is helping learners to improve planning and find answers by himself. 


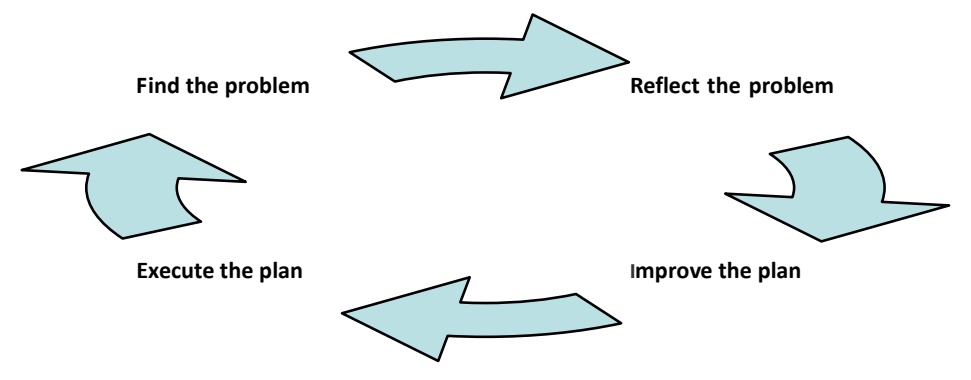

Figure. 1 Cycle process of Action learning

Actually, each link includes the process of reflecting. We can discover new problems or plan by reflecting the confusion. Everybody in the action learning team tries their best to support learners. Then the activity format a cycle.

\section{The key element}

There are four key elements in the dynamic process of action learning. We know action play an important part in the group learning process from the formula" $\mathrm{L}=\mathrm{P}+\mathrm{Q}$ ". It begins with finding the problem. Its direct purpose is to solve the question. The problem will continue to produce with the learners' further study.

Questions play a key role in the action learning. Problems can be strategic such as" how can I solve it in this case? ". It also can be operational such as "what can I do next?'It also can be a challenge question such as "I want to solve it, but I don't know is it feasible or not?". All these problems have several solutions.

There are three scenarios after problems. First, the learner is able to make a clear description of the problem such as "I know what the problem is"'I know how to do it". The learner makes a plan before discussion. Student group helps to reflect and reconstruct a more practical action plan. Second, learners encounter difficulties in practice. But he is unable to describe the problem clearly such as "I don't know where is the problem? ""Can anyone help me to analyze it? "Learner should make a feasible action plan with the help of the learning team. These links must reflect on practical experience. Third, the learner can clearly describe the problem sometimes. But he can't find out the feasible solutions. Such as "I know what the problem is at present, but I haven't got a clue to deal with it. " Can anyone give me a help?" .Plan can be made through self-reflection by Learner's thinking. The plan is the essential factor in the process of active learning. It is premised condition of action. There is no new problem without action. Finally, it can promote learners to reflect on the question.

Action is an independent execution of a practice learning process. The learner can implement their plan by a variety of other learning methods. He may seek help from others by collecting data or checking. Action learning closely links the theory and practice on the basis of action. It is not mechanically complete plan. These processes contain continuous introspection and reflection.

Reflection has an effect throughout the process of active learning. Reflection includes learner's self-reflection and cooperation. It's not enough to have the learner's self-reflection because the act of 
reflection is often not clear or systematic. It cannot guide the learner. The structured organization can be better than the traditional learning process.

\section{The results of the action learning}

There are two results of the Action learning. One is to improve learners' transformation. It is a process of solving problems. We know learner isn't only using his own knowledge, but also use other group members' knowledge. The value of the action learning is changing the individual ideas and attitude from the formula " $\mathrm{L}=\mathrm{P}+\mathrm{Q}$." The transition is mainly performance in two aspects: one is to improve learners' knowledge and skills. The learning process is directly involved in the practice. So the knowledge is not dogma. They are flexible ability. Learner can obtain the skill of finding issues. The other one is promoting the transition of learner' emotion. It is a process of personal growing.

The second aspect is promoting the transformation of organizations. Learners have been changed through solving practical problems. The organization is eager to solve the reality difficulties. The problem can be divided into several smaller questions through the action learning. It is a shift of the organization. The initiatives of the learner have been improved rapidly. Participants in the team have become a force to reform the organization. The subtle changes will affect those who have not been involved in the meeting of action learning. The learning organization will naturally form when more people are involved in it.

\section{Summary}

Learning content is segmented in traditional learning. Action learning perfect solves these problems. The learner can clearly understand his current situation. Lerner first shows his confusion to everyone on the group meeting. Team participants assist the learner to solve problems. It can find problem through practice first. Then solve the practice problems.

The learning activity format a cycle. The important thing is finding the problem. The learner can reflect the problem from the action learning group. Then a new plan will be improved at the group meeting. Finally, learner executes the plan. The new problem will happen again trough the execution of the plan.

Action learning has become a vital means of the personal development. It can easily solve the practical problems. The learner in the group meeting doesn't rely on the teacher's guidance. They can obtain self development rapidly. The method enhances communication of different department. In fact, it can improve the core competitiveness of the organization.

\section{References}

[1] Research and Development of Classroom Action Research Process to Enhance School Learning, Volume 171, 16 January 2015, Pages 1315-1324.

[2] Michael J. Marquardt. Optimizing the Power of Action Learning, Nicholas Brealey Publishing Limited. 2011.

[3] Alf Lizzio\& Keithia Wilson. Active Learning in Higher Education: an investigation of its potential to develop professional capability [J] . Studies in Higher Education vol8 (2004) . 
[4] Koo, L.C. "Learning Action Learning” Journal of Workplace Learning, (1999)Vol 11, Number 3, pp. 89-94.

[5] Alison Bone\&Tom Bourner, Action learning for university Administrators [J]. Vol 2 (1999).

[6] Huang haochen. The research on a new mode of student affairs based on the theory of the collaborative innovation, International Congress of Arctic Social Sciences, vol3 (2014).

[7] Ian McGill\&Anne Brockbank, The Action Learning Handbook [M]. London, 2003.

[8] Graham Paton, A Systemic Action Learning Cycle as the Key Element of an Ongoing Spiral of Analyses [J]. Systemic Practice and Action Research.(2001) Vol.14, No. 1.

[9] Robin C. Burgess. Reflective practice: action learning sets for managers in social work [J]. Social work education, Vol. 18, no. 3 (1999).

[10] David Kember, Action Learning and Action Research [M] . London and New York: Kogan Page, (2000). 